\title{
Percutaneous Closure of Ductus Arteriosus with the Amplatzer Prosthesis. The Brazilian Experience
}

\author{
Luiz Carlos Simões, Carlos A. C. Pedra, César A. Esteves, Ronaldo Camargo, Sérgio L.N. Braga, \\ Pedro Loureiro, Marco Aurélio Santos, Valmir Fernandes Fontes
}

São Paulo, SP - Rio de Janeiro, RJ - Brazil

\begin{abstract}
Objective - To report the results of percutaneous occlusion of persistent ductus arteriosus with the Amplatzer prosthesis in 2 Brazilian cardiological centers.

Methods - From May 1998 to July 2000, 33 patients with clinical and laboratory diagnosis of persistent ductus arteriosus underwent attempts at percutaneous implantation of the Amplatzer prosthesis. The median age was 36 months (from 6 months to 38 years), and the median weight was $14 \mathrm{~kg}$ (from 6 to $92 \mathrm{~kg}$ ). Sixteen patients $(48.5 \%$ ) were under 2 years of age at the time of the procedure. All patients were followed up with periodical clinical and echocardiographic evaluations to assess the presence and degree of residual shunt and possible complications, such as pseudocoarctation of the aorta and left pulmonary artery stenosis.
\end{abstract}

Results - The minimum diameter of the arterial ducts ranged from 2.5 to 7.0mm (mean of 4.0 \pm 1.0 , median of 3.9). The rate of success for implantation of the prosthesis was $100 \%$. Femoral pulse was lost in 1 patient. The echocardiogram revealed total closure prior to hospital discharge in 30 patients, and in the follow-up visit 3 months later in the 3 remaining patients. The mean follow-up duration was 6.4 3.4 months. All patients were clinically well, asymptomatic, and did not need medication. No patient had narrowing of the left pulmonary artery or of the aorta. No early or late embolic events occurred, nor did infectious endarteritis. A new hospital admission was not required for any patient.

Conclusion - The Amplatzer prosthesis for persistent ductus arteriosus is safe and highly effective for occlusion of ductus arteriosus of varied diameters, including large ones in small symptomatic infants.

Keywords: persistent ductus arteriosus, percutaneous occlusion, Amplatzer prosthesis

Instituto Dante Pazzanese de Cardiologia - São Paulo and Instituto Nacional de Cardiologia Laranjeiras - Rio de Janeiro

Mailing address: Carlos A. C. Pedra - Instituto Dante Pazzanese de Cardiologia Av. Dr. Dante Pazzanese, 500 - 04012-180 - São Paulo, SP, Brazil E-mail: vffontes@uol.com.br

English version by Stela Maris C. e Gandour
A number of devices have been used in the percutaneous treatment of ductus arteriosus since the introduction of the technique by Porstman et al in $1967^{1,2}$. Because of the simplicity of the procedure, its low cost, good efficacy, and low rate of complications, the Gianturco coil became the most used device with an undeniable application for short ductus arteriosus ${ }^{3-5}$. However, the approach of a ductus arteriosus larger than $3-3.5 \mathrm{~mm}$ with this method, in addition to the association with a greater rate of embolism, requires adaptations in the implantation technique, multiple devices, and the use of coils for controlled delivery or larger in size ${ }^{6-10}$. The Rashkind umbrella, better indicated for these situations ${ }^{3}$, was recently withdrawn from the market because of its significant degree of residual shunt ${ }^{11}$. After the publication of the results of convincing experimental studies ${ }^{12}$, the Amplatzer prosthesis for percutaneous occlusion of ductus arteriosus was introduced for clinical application with encouraging results ${ }^{13,14}$. Our study reports the experience with the Amplatzer prosthesis in 2 important Brazilian pediatric cardiology centers.

\section{Methods}

From May 1998 to July 2000, 33 patients (13 males and 20 females) underwent percutaneous implantation of the Amplatzer prosthesis. All patients or their guardians provided formal written consent after a detailed explanation of the risks and benefits of the procedure was provided. Age ranged from 6 months to 38 years (median 36 months) and weight ranged from 6 to $92 \mathrm{~kg}$ (median $14 \mathrm{~kg}$ ). Sixteen $(48.5 \%$ ) patients were under 2 years of age at the time of the procedure. In all patients, a continuous murmur could be heard in the left infraclavicular region, and two-dimensional transthoracic echocardiography with color flow Doppler was used to make a diagnosis. Signs of volumetric hypertrophy of the left atrium and ventricle were documented on echocardiography or angiography in all patients. In regard to associated lesions, a 14-month-old patient had a minimum muscular ventricular septal defect with no clinical or hemodynamic repercussions. 
The Amplatzer prosthesis (AGA Medical Corporation, Golden Valley MN, USA) for occlusion of ductus arteriosus is a self-expanding device, in the shape of a mushroom or bullet, consisting of a 0.004-inch-thick metallic net of nitinol with an intrinsic memory (fig. 1) ${ }^{12,13}$. A distal retention disc or skirt exists, $4 \mathrm{~mm}$ larger than the diameter of the device, to provide anchorage of the duct in the aortic ampulla. Flaps of polyester fibers are sewn to the metallic net in the inner portion of the device, accounting for the induction of local thrombosis with consequent interruption of flow through the ductus arteriosus. A stainless steel female pin is welded with a laser in the proximal extremity of the device. The stainless steel delivery cable connects to the female pin through a screw mechanism. A sheath of the Mullins type (manufactured by AGA), a plastic charger, and a device to rotate the delivery cable complete the implantation system.

The prosthesis is available in 5 sizes, corresponding to the 2 diameters of the inner cone, one more proximal and the other close to the retention disc (fig. 1). The 6-4 and 8-6 prostheses are $7 \mathrm{~mm}$ long and the remaining are $8 \mathrm{~mm}$. The profile of the sheaths required for implantation ranges from 5 to $7 \mathrm{Fr}$, according to the diameter of the device selected (tab. I).

A routine diagnostic left-to-right catheterization was performed in all patients before the implantation. A 4 or $5 \mathrm{Fr}$ introducer was used for the femoral artery and a 6 or $7 \mathrm{Fr}$ for

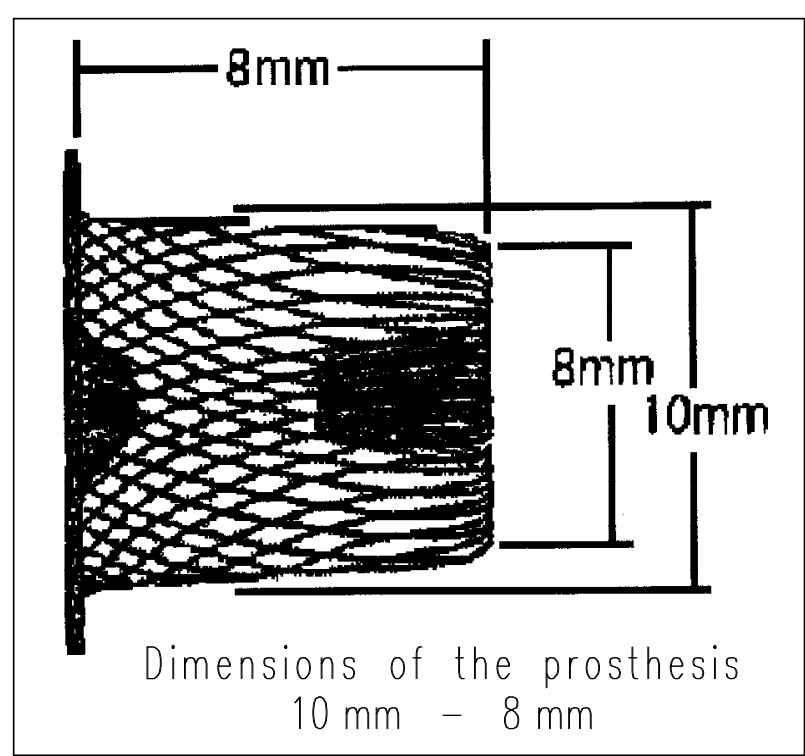

Fig. 1 - Design of the profile of the prosthesis, showing its proximal and distal dimensions close to the retention disc.

Table I - Dimensions of the prostheses and profile of the sheaths required for implantation

\begin{tabular}{|ccc|}
\hline Prosthesis & Sheath & Extension \\
\hline $6-4$ & $5-6 \mathrm{Fr}$ & $7 \mathrm{~mm}$ \\
$8-6$ & $5-6 \mathrm{Fr}$ & $7 \mathrm{~mm}$ \\
$10-8$ & $6-7 \mathrm{Fr}$ & $8 \mathrm{~mm}$ \\
$12-10$ & $6-7 \mathrm{Fr}$ & $8 \mathrm{~mm}$ \\
$14-12$ & $6-7 \mathrm{Fr}$ & $8 \mathrm{~mm}$ \\
\hline
\end{tabular}

the vein. General anesthesia with orotracheal intubation or a laryngeal mask was used for infants and children according to the local practice in each center ${ }^{15}$. Heparin was used according to the operator's preference (initial dose ranging from 75 to $150 \mathrm{U} / \mathrm{kg}$ ). Aortography of the descending aorta in the left lateral view was performed to characterize the ductus arteriosus, according to Krishenko's classification ${ }^{16}$, and to measure its smallest diameter through the digital method with correction of the magnification. A guidewire with a straight tip was used to cross the ductus arteriosus, moving from the pulmonary artery to the aorta, and a catheter with a terminal orifice (Judkins type for right coronary artery, or Lehman, or multipurpose) was positioned in the descending aorta. This catheter was replaced by the long sheath of the Mullins type (AGA) on top of a 0.035 " replacement guidewire. The guide and the dilator were withdrawn, and the sheath was left in the descending aorta. According to previous experimental studies and clinical experience, the device chosen for implantation should be 1 to $2 \mathrm{~mm}$ larger than the minimum diameter of the ductus arteriosus, taking into account the most proximal diameter of the cone of the prosthesis, which actually lies inside the ductus arteriosus trajectory. For example, for a ductus arteriosus of $4 \mathrm{~mm}$, the 8 6 prosthesis was selected. This chosen prosthesis was then screwed into the distal extremity of the delivery cable and, under a water seal, was pulled into the plastic charger, introduced into the Mullins sheath. The cable was then carefully pushed without being rotated, and the prosthesis was advanced as far as the distal extremity of the sheath in the descending aorta. The distal disc of the prosthesis was opened in the descending aorta, and the sheath was pulled slightly on top of the cable. The entire system (sheath and lead) was then pulled as a unit until the distal disc or skirt remained well coupled in the aortic ampulla of the ductus arteriosus. This position was confirmed by small injections of contrast medium with the aid of an arterial catheter. Maintaining mild tension in the delivery cable, the sheath was then pulled over the latter, releasing the body of the prosthesis inside the trajectory of the ductus arteriosus. A new aortography was performed to confirm the position of the prosthesis when the latter was still connected to the delivery cable. In case of unsatisfactory positioning, the prosthesis was replaced inside the sheath and repositioned after being moved forward through the ductus arteriosus. If an adequate position was confirmed, the prosthesis was released by turning the delivery cable in a counterclockwise direction with the aid of the plastic device connected to the proximal extremity of the lead. A final aortography was performed 5 to 15 minutes after implantation to assess the presence and the degree of the residual shunt (figs. 2A to 2E).

The patients were awakened and extubated while still in the catheterization laboratory after hemostasis was obtained through local manual compression. They were then transferred to a postanesthesia unit for clinical observation.

On the following morning, a chest X-ray was taken to verify the position of the prosthesis, and two-dimensional color flow Doppler echocardiography was performed to as- 

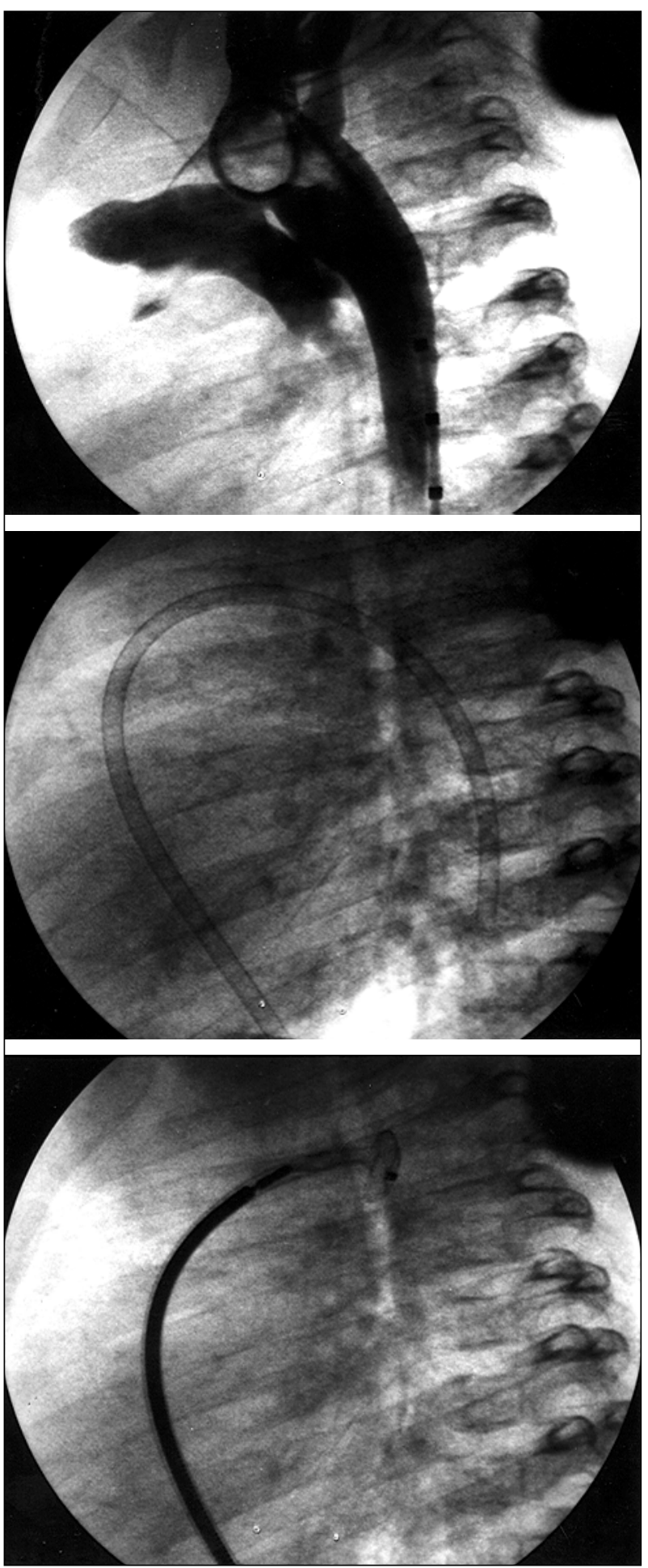

Fig. 2 - Sequence of implantation of the Amplatzer device in ductus arteriosus. A) aortography in descending aorta showing ductus arteriosus of the conical type (A of Krishenko), measuring $3.8 \mathrm{~mm}$ in its narrower point; B) after anterograde crossing of the duct, a long Mullins sheath is left in the descending aorta; C) the prosthesis is advanced inside the sheath and delivered in the aorta. The entire system is pulled towards the duct, with anchorage of the distal disc in the aortic ampulla.

sess the presence and degree of residual shunt, and also the existence of possible narrowing in the left pulmonary artery and descending aorta. Serial clinical evaluations accompanied by a new echocardiography test were performed accor-
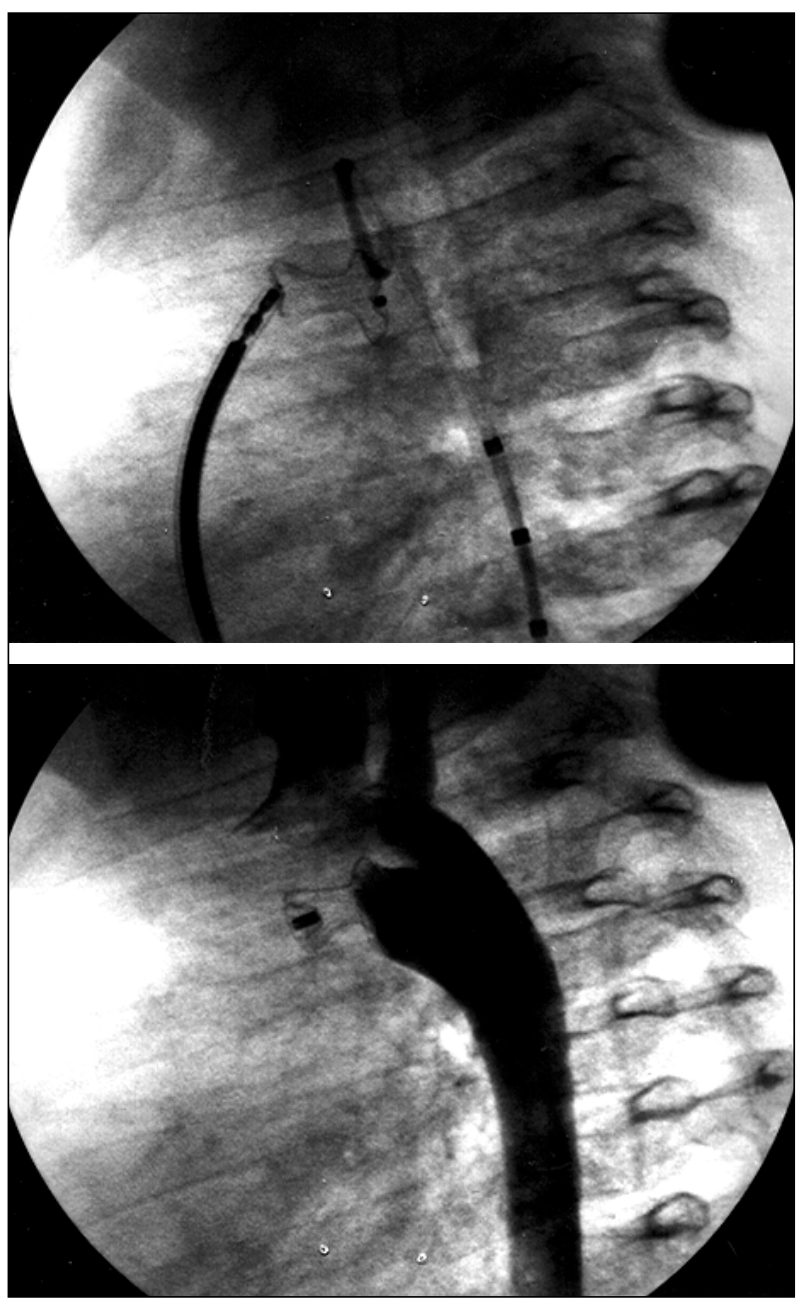

Fig. 2 - D) The most proximal portion is exteriorized after retraction of the sheath on top of the delivery cable. An aortography confirms the appropriate position of the device, with no protrusion to the aorta or pulmonary artery, with the device still connected to the delivery cable. At this point, recapture of the prosthesis to the interior of the sheath and its repositioning are still possible; E) aortography performed 10 minutes after delivery of the prosthesis showing total closure of the ductus arteriosus while still in the catheterization laboratory.

ding to the cardiologist in charge, usually $1,3,6$, and 12 months after the procedure. In cases of isolated persistent ductus arteriosus, prophylaxis of infectious endarteritis was recommended for 6 months until endothelialization of the prosthesis occurred. In cases with associated lesions, prophylaxis was recommended according to the current guidelines of the American Heart Association.

The values are expressed in mean and standard deviation or median and variance as indicated.

\section{Results}

Clinical data and results of all patients are listed in table II. The minimum diameter of the ductus arteriosus ranged from 2.5 to $7.0 \mathrm{~mm}$ (mean of $4.01 \pm 1.0$ and median of 3.90). Qp/ Qs, measured according to Fick's technique in 12 patients, ranged from 1.8 to 3.2 with a mean of $2.2 \pm 0.5$. Six patients were under 1 year of age, were symptomatic, and used anti- 


\begin{tabular}{|c|c|c|c|c|c|c|c|c|c|c|}
\hline Patient & Age months & Weight $\mathrm{kg}$ & Sex & MDDA & Type & Prosthesis & Fluoro & IRS & Follow-up & LRS \\
\hline 1 & 27 & 11.9 & $\mathrm{~F}$ & 4.8 & A & $8-6$ & 10.1 & $\mathrm{~N}$ & 6 & $\mathrm{~N}$ \\
\hline 2 & 17 & 10.0 & $\mathrm{~F}$ & 3.8 & E & $8-6$ & 12.7 & D & 3 & $\mathrm{~N}$ \\
\hline 3 & 24 & 12.9 & $\mathrm{~F}$ & 4.1 & A & $8-6$ & 13.0 & $\mathrm{~N}$ & 6 & $\mathrm{~N}$ \\
\hline 4 & 9 & 8.7 & $\mathrm{~F}$ & 3.9 & A & $8-6$ & 9.6 & $\mathrm{~N}$ & 6 & $\mathrm{~N}$ \\
\hline 5 & 21 & 9.9 & $\mathrm{~F}$ & 3.8 & E & $8-6$ & 16.4 & $\mathrm{~N}$ & 6 & $\mathrm{~N}$ \\
\hline 6 & 51 & 17.0 & $\mathrm{~F}$ & 3.5 & $\mathrm{C}$ & $6-4$ & 8.9 & $\mathrm{~N}$ & 3 & $\mathrm{~N}$ \\
\hline 7 & 18 & 13.0 & $\mathrm{M}$ & 3.9 & A & $8-6$ & 9.4 & $\mathrm{~N}$ & 6 & $\mathrm{~N}$ \\
\hline 8 & 36 & 15.6 & $\mathrm{M}$ & 5.6 & A & $10-8$ & 11.8 & $\mathrm{~N}$ & 6 & $\mathrm{~N}$ \\
\hline 9 & 88 & 24.0 & $\mathrm{~F}$ & 3.3 & A & $6-4$ & 10.3 & $\mathrm{~N}$ & 6 & $\mathrm{~N}$ \\
\hline 10 & 34 & 14.1 & $\mathrm{M}$ & 4.4 & A & $8-6$ & 11.2 & $\mathrm{~N}$ & 6 & $\mathrm{~N}$ \\
\hline 11 & 144 & 29.0 & $\mathrm{~F}$ & 3.4 & A & $8-6$ & 7.6 & $\mathrm{~N}$ & 6 & $\mathrm{~N}$ \\
\hline 12 & 48 & 21.2 & $\mathrm{~F}$ & 3.4 & A & $6-4$ & 10.7 & $\mathrm{~N}$ & 6 & $\mathrm{~N}$ \\
\hline 13 & 192 & 72.0 & $\mathrm{M}$ & 3.3 & A & $6-4$ & 11.4 & $\mathrm{~N}$ & 6 & $\mathrm{~N}$ \\
\hline 14 & 408 & 68.0 & $\mathrm{~F}$ & 4.4 & E & $8-6$ & 10.9 & $\mathrm{~N}$ & 6 & $\mathrm{~N}$ \\
\hline 15 & 456 & 74.0 & $\mathrm{~F}$ & 4.5 & A & $8-6$ & 14.2 & $\mathrm{~N}$ & 6 & $\mathrm{~N}$ \\
\hline 16 & 38 & 14.6 & $\mathrm{M}$ & 3.3 & A & $6-4$ & 7.9 & $\mathrm{~N}$ & 6 & $\mathrm{~N}$ \\
\hline 17 & 8 & 6.5 & $\mathrm{M}$ & 4.6 & A & $8-6$ & 12.9 & D & 3 & $\mathrm{~N}$ \\
\hline 18 & 64 & 18.7 & $\mathrm{~F}$ & 5.6 & $\mathrm{C}$ & $10-8$ & 13.3 & $\mathrm{~N}$ & 6 & $\mathrm{~N}$ \\
\hline 19 & 17 & 9.0 & $\mathrm{~F}$ & 3.1 & E & $6-4$ & 8.2 & $\mathrm{~N}$ & 6 & $\mathrm{~N}$ \\
\hline 20 & 24 & 10.0 & $\mathrm{~F}$ & 2.5 & A & $6-4$ & 8.7 & $\mathrm{~N}$ & $<3$ & - \\
\hline 21 & 24 & 10.0 & $\mathrm{~F}$ & 2.5 & A & $8-6$ & 11.7 & $\mathrm{~N}$ & $<3$ & - \\
\hline 22 & 9 & 6.0 & $\mathrm{~F}$ & 5.6 & C & $8-6$ & 6.3 & $\mathrm{~N}$ & 12 & $\mathrm{~N}$ \\
\hline 23 & 14 & 7.2 & $\mathrm{M}$ & 2.5 & A & $6-4$ & 6.6 & $\mathrm{~N}$ & 12 & $\mathrm{~N}$ \\
\hline 24 & 54 & 16.4 & $\mathrm{M}$ & 3.0 & A & $6-4$ & 6.6 & $\mathrm{~N}$ & 12 & $\mathrm{~N}$ \\
\hline 25 & 288 & 70.0 & $\mathrm{~F}$ & 3.0 & C & $8-6$ & 6.0 & $\mathrm{~N}$ & 12 & $\mathrm{~N}$ \\
\hline 26 & 48 & 15.0 & $\mathrm{~F}$ & 2.8 & A & $6-4$ & 8.0 & $\mathrm{~N}$ & 12 & $\mathrm{~N}$ \\
\hline 27 & 6 & 6.5 & $\mathrm{M}$ & 4.0 & A & $8-6$ & 25.3 & $\mathrm{~N}$ & 12 & $\mathrm{~N}$ \\
\hline 28 & 408 & 92.0 & $\mathrm{M}$ & 3.4 & A & $8-6$ & 12.0 & $\mathrm{~N}$ & 12 & $\mathrm{~N}$ \\
\hline 29 & 168 & 54.0 & $\mathrm{~F}$ & 4.0 & A & $8-6$ & ND & $\mathrm{N}$ & 6 & $\mathrm{~N}$ \\
\hline 30 & 23 & 14.0 & $\mathrm{M}$ & 7.0 & A & $12-10$ & ND & $\mathrm{N}$ & 6 & $\mathrm{~N}$ \\
\hline 31 & 16 & 9.8 & $\mathrm{~F}$ & 4.0 & A & $8-6$ & ND & $\mathrm{N}$ & $<3$ & \\
\hline 32 & 10 & 6.0 & $\mathrm{M}$ & 4.0 & A & $8-6$ & ND & $\mathrm{N}$ & $<3$ & \\
\hline 33 & 10 & 7.0 & $\mathrm{M}$ & 4.5 & E & $8-6$ & ND & $\mathrm{N}$ & $<3$ & \\
\hline
\end{tabular}

congestive medication. In these patients, the mean weight was $6.8 \pm 1.0 \mathrm{~kg}$ ( 6 to $8.7 \mathrm{~kg}$ ), and the minimum diameter of the ductus arteriosus was $4.4 \pm 0.6 \mathrm{~mm}$ ( 3.9 to $5.6 \mathrm{~mm}$ ). According to Krishenko's classification, 24 patients had ductus arteriosus of the A type, 5 patients of the E type, and 4 patients of the $C$ type. In all patients, the prosthesis was successfully implanted. The prostheses used were $6 / 4$ (10 patients), $8 / 6$ (20 patients), 10/8 ( 2 patients), and 12/10 (1 patient). The mean of the smallest diameter of the prosthesis was $5.6 \pm 1.4$ $\mathrm{mm}$. The duration of fluoroscopy was $10.8 \pm 3.7$ minutes, and the duration of the procedure was $80.6 \pm 15.5$ minutes. In all patients, the continuous murmur disappeared immediately after implantation of the prosthesis. No patient required a blood transfusion. In regard to complications, an arterial pigtail catheter broke when it was being removed. The intravascular fragment was rescued with some difficulty with a snare catheter introduced through the contralateral artery. This patient evolved with loss of the femoral pulses bilaterally and did not respond to the use of thrombolytic therapy. Except for this patient, all the others were discharged on the day following the procedure. Echocardiography prior to discharge revealed total closure in 30 patients. The 3 remaining patients had a mild residual shunt, which is in accordance with results in previously published protocols ${ }^{3}$. Nar- rowing of the left pulmonary artery or aorta was not seen in any patient.

During follow-up, the patient who evolved with loss of femoral pulses underwent a new catheterization 10 months after the initial procedure. Both femoral arteries were occluded, an extensive local net of collateral circulation existed, and no narrowing in the aorta caused by the prosthesis could be seen. Twenty-eight patients completed at least 3 months of follow-up, all of them had total closure of the defect documented on echocardiography, and no stenosis in the left pulmonary artery and descending aorta was evidenced. In the 5 remaining patients with a follow-up shorter than 3 months, the 24-hour echocardiogram already showed total closure of the ductus arteriosus. The mean follow-up duration was $6.4 \pm 3.4$ months. No late embolic event, need for readmission, or infectious endarteritis occurred. All patients were clinically well, asymptomatic, and did not require medication.

\section{Discussion}

Our study reports the initial experience of 2 important Brazilian centers in the closure of ductus arteriosus with interventional catheterization, using a new prosthesis. 
Because of the previous solid experience of both institutions in the percutaneous handling of this defect ${ }^{1,3,6}$, in addition to the excellent intrinsic properties of the prosthesis, we practically had no learning curve. The results found were very good, with a $100 \%$ success rate for implantation and total closure. The system proved to be simple, safe, easy to handle and learn, and had a very low probability of embolization due to totally controlled delivery. The arterial complication observed did not result from the closure procedure itself, and it may even happen in diagnostic catheterizations.

The system provides considerable advantages, almost reaching the ideal characteristics for this type of procedure. Implantation is performed by an anterograde route, using introducers and sheaths of low profile, minimizing the risk of vascular damage, and enabling the approach in low-weight patients. Therefore, the arterial route is used only for performing angiographies with low-profile catheters, which also allows complete monitoring of the position of the prosthesis at any stage of the procedure. If the position is not satisfactory, the device may be replaced in the sheath and repositioned until the ideal place for final delivery is achieved. Due to the memory of nitinol thermal memory stent, this maneuver may be repeated as many times as necessary, without deformation of the metallic net of the device. For the 10-8, 12-10, and 14-12 devices, even though the manufacturer claims that the implantation is feasible when 6 Fr sheaths are used, we recommend, whenever possible, the use of 7 Fr sheaths to avoid any difficulty in rescuing the prosthesis if repositioning is required.

According to previous publications ${ }^{3}$, symptomatic infants under 1 year of age with large ductus arteriosus benefit the most from this new technique. This was shown in our initial experience, in which 6 infants with wide ductus arteriosus (mean of $5.6 \mathrm{~mm}$ ) had their defects occluded in a simple, safe, and effective way. This would have been difficult or even impossible with other prostheses. This technique is still not suitable for use in neonates and infants weighing less than $4 \mathrm{~kg}$.

Even though we have not approached the B and D angiographic types in our initial experience, the system has a potential application for all types of ductus arteriosus. We speculate that the Amplatzer prosthesis may result in disorders in flow or even stenoses in the descending aorta or in the pulmonary artery when performed in small infants with type $B$ ductus arteriosus (window type). This situation is not difficult to imagine, considering the small size of the vascular structures in this age bracket, the 7- or 8-mm length of the prosthesis, and the reduced space in the trajectory of this type of defect to its anchorage. Significant aortic obstruction was reported in a 2 -year-old patient, caused by malpositioning of the prosthesis, and required surgical removal ${ }^{17}$. This is less crucial in older children, whose vessels have larger diameters.

The world experience with this prosthesis grows exponentially ${ }^{18-22}$. In the last meeting of the participants in multicenter studies of the Amplatzer prostheses (for ductus arte- riosus, atrial septal defect, ventricular septal defect, and persistence of the oval foramen) held in Strasbourg, France, in June 2000, the number of cases of closure of the ductus arteriosus was close to 1,000 . The success rate of implantation is higher than $97 \%$, and no case of residual shunt has been reported (efficacy of 100\%). Embolism is a rare occurrence, as are complications, which are usually minor, including self-limited hemolysis ${ }^{23}$ and reduction in femoral pulses. Only 1 death has been reported as a direct result of the procedure (David Nykanen, The Hospital for Sick Children, Toronto, ON, Canada, personal communication). The patient was 2.5-years-old, had Down's syndrome and severe pulmonary hypertension. The prosthesis used (6-4) was too small for the minimum diameter of the duct $(4 \mathrm{~mm})$. Early embolism $(<1 \mathrm{~h})$ in the descending aorta and impairment of blood flow to the mesenteric bed occurred. Even though rescue was performed 4 hours after embolism with a Cook 3 Fr bioptome for endomyocardial biopsy by an anterograde route, irreversible vascular distress occurred, being followed by bacterial intestinal translocation with installation of sepsis of an abdominal origin, multisystem organ failure, and death. The postmortem examination revealed grade IV pulmonary hypertension according to the Heath-Edwards criteria. Because of this episode, the use of Amplatzer prostheses for closure of ventricular septal defects (with double retention disc) is speculated to be more appropriate for approaching large ducts with severe reactive pulmonary hypertension. Another lesson learned from this episode is that, due to its high thrombogenic potential, the prosthesis may rapidly interrupt the flow to distal structures, requiring immediate rescue if it affects vital structures. Due to the presence of nickel in the metallic alloy that forms nitinol, some authors have drawn attention to the possibility of its toxicity. But this has not found support in clinical practice, where implantations have been reported, including in patients with a cutaneous allergy to the metal, and no reaction has been found (III Symposium on Amplatzer prostheses, Strasbourg, France). The absence of toxic side effects has also been confirmed with the widespread use of the Amplatzer prosthesis for atrial septal defect (more than 4,000 cases) (Dr. Ziyad Hijazi, personal communication). A long-term careful clinical follow-up will elucidate this question.

Recognizing its cost as one limitation in our environment, we believe that the Amplatzer prosthesis should be reserved for larger ducts ( $>4 \mathrm{~mm})$. Smaller ducts (2.5-3.0mm), mainly the conical ones, can and should be occluded with coils because of their low cost, simplicity and the efficacy of the technique. Ducts between 3 and $4 \mathrm{~mm}$, also of the conical type, may be approached with multiple coils (the Gianturco coil or that of controlled delivery), depending on the operator's personal experience and skill. However, the use of the Amplatzer prosthesis in these cases makes the procedure simpler and more effective ${ }^{20}$. Due to the versatility of the implantation system and to the already cited characteristics of the Amplatzer prosthesis, it has also been used for closing other vascular defects and malformations, such as coronary and arteriovenous pulmonary fistulas, 
systemic-pulmonary shunts (Blalock-Taussig), systemicpulmonary collaterals, and veno-venous collaterals after Glenn surgery, the fenestrated Fontan operation, and other procedures ${ }^{24-26}$.

In conclusion, the Amplatzer prosthesis has features that make it the best prosthesis ever designed for percutaneous treatment of ductus arteriosus. It has almost all characteristics considered ideal for treating a simple disease with excellent prognosis that may and should be treated in a nonsurgical way, whenever possible.

\section{References}

1. Pedra CAC, Esteves CA, Braga SLN, Kambara A, Fontes VF. Oclusão percutânea do canal arterial: Estado da Arte. Rev Bras Cardiol Inv 1997; 5: 22-35.

2. Porstman W, Wierny L, Warnke H. Closure of persistent ductus arteriosus without thoracotomy. Ger Med Mon 1967; 12: 259-61.

3. Pedra CAC, Pedra SRFF, Esteves CA, et al. Experiência global no fechamento percutâneo do canal arterial. Arq Bras Cardiol 1998; 71: 769-80.

4. Lloyd TR, Fedderly R, Medelsohn AM, Sandhu SK, Beekman RHIII. Transcatheter occlusion of patent ductus arteriosus with Gianturco coils. Circulation 1993; 88: 1412-20.

5. Hijazi ZM, Geggel RL. Results of anterograde transcatheter closure of patent ductus arteriosus using single or multiple Gianturco coils. Am J Cardiol 1994; 74: 925-9.

6. Simões LC, Santos MA, Tavares V, etal. Segunda Espira durante ofechamento percutâneo do ducto arterioso: Quando decidir-se já no primeiro procedimento. Rev Soc Cardiol Rio Janeiro 1999; 12(supl A): 99.

7. Sommer RJ, Gutierrez A, Lai WW, Parness IA. Use of preformed Nitinol snare to improve transcatheter coil delivery in occlusion of patent ductus arteriosus. Am J Cardiol 1994; 74: 836-9.

8. Kuhn MA, Latson LA. Transcatheter embolization coil closure of patent ductus arteriosus - modified delivery for enhanced control during coil positioning. Cathet Cardiovasc Diagn 1995; 36: 288-90.

9. Esteves CA, Pedra CAC, Braga SLN, Fontes VF. Implante assistido de coil no canal arterial através da ajuda de um cateter balonado. Rev Bras Cardiol Inv 1997; 5: 6-11.

10. Owada CY, Teitel DF, Moore P. Evaluation of Gianturco coils for closure of large (>3.5mm) patent ductus arteriosus. J Am Coll Cardiol 1997; 30: 1856-62.

11. Hosking MCK, Benson LN, Musewe N, Dyck JD, Freedom RM. Transcatheter occlusion of the persistently patent ductus arteriosus: fourty-month follow-up and prevalence of residual shunting. Circulation 1991; 84: 2313-7.

12. Sharafuddin MJ, Gu X, Titus JL, et al. Experimental evaluation of a new sel-expanding patent ductus arteriosus in a canine model. J Vasc Interv Radiol 1996; 7 : 877-87.

13. Masura J, Walsh KP, Thanopoulous B, et al. Catheter closure of moderate-to largesized patent ductus arteriosus using the new Amplatzer duct occluder: immediate and short term results. J Am Coll Cardiol 1998; 31: 878-82.
14. Simões LC, Santos MA, Oliveira PS, et al. Fechamento percutâneo de ductos moderados a grandes com prótese de Amplatzer. Rev Soc Cardiol Rio Janeiro 1999; 12(supl A): 100 .

15. Ibiapina RCP, Pedra CAC, Costa LR, et al. Implicações anestésicas em Cardiologia Invasiva Pediátrica. Rev Bras Cardiol Inv 1998; 6: 35-40.

16. Krishenko A, Benson LN, Burrows P, Moes CAF, McLaughlin P, Freedom RM Angiographic classification of the isolated, persistently patent ductus arteriosus and implications for percutaneous occlusion. Am J Cardiol 1989; 67: 877-80.

17. Duke C, Chan KC. Aortic obstruction caused by device occlusion of patent arterial duct. Heart 1999; 82: 109-11.

18. Thanoppoulos BD, Hakim FA, Hiari A, Goussous Y, Basta E, Zarayelyan AA, Tsaousis GS. Further experience with transcatheter closure of the patent ductus arteriosus using the Amplatzer duct occluder. J Am Coll Cardiol 2000; 35: 1016-21.

19. Podnar T, Gavora P, Masura J. Percutaneous closure of patent ductus arteriosus: complementary use of detachable Cook PDA coils and Amplatzer duct occluders. Eur J Pediatr 2000; 159: 293-6.

20. Simões LC, Santos MA, Camargo R, et al. Fechamento percutâneo do ducto arterioso maior de 3.8mm em lactentes e pré escolares: Prótese de Amplatzer ou múltiplos coils. Arq Bras Cardiol 2000; 74(supl I ): 23.

21. Marwah A, Radhakrishnan S, Shrivastava S. Immediate and early results of closure of moderate to large patent arterial ducts using the new Amplatzer device. Cardiol Young 2000; 10: 208-11.

22. Saliba Z, Aggoun Y, Hausse AO, et al. Percutaneous closure of patent ductus arteriosus with the Amplatzer duct occluder. Arch Mal Coeur Vaiss 2000; 93: 533-8.

23. GodartF, Rodes J, Rey C. Severe haemolysis after transcatheter closure of a patent arterial duct with the new Amplatzer duct occluder. Cardiol Young 2000; 10: 265-7.

24. Tofeig M, Walsh KP, Arnold R. Transcatheter occlusion of a post-Fontan residual hepatic vein to pulmonary venous atrium communication using the Amplatzer septal occluder. Heart 1998; 79: 624-6.

25. Pedra CAC, Pihkala J, Nykanen DG, Benson LN. Antegrade transcatheter closure of coronary artery fistulae using vascular occlusion devices. Heart 2000; 83: 94-6.

26. Chessa M, Chaudhari M, DeGiovanni JV. Aorto-left ventricular tunnel: transcatheter closure using an Amplatzer duct occluder device. Am J Cardiol 2000; 86 253-4. 